\title{
Health vulnerability to flood-induced risks of households in flood-prone informal settlements in the Coastal City of Mombasa, Kenya
}

\author{
Fredrick Okoth Okaka' ${ }^{1} \cdot$ Beneah D. O. Odhiambo ${ }^{1}$
}

Received: 6 March 2018 / Accepted: 11 September 2019 / Published online: 19 September 2019

(c) The Author(s) 2019

\begin{abstract}
Floods have serious consequences on community well-being and health. This study was intended to address the health vulnerability of households in flood prone informal settlements in the coastal city of Mombasa in Kenya and their adaptation measures. Mombasa City has a history of floods, in the recent past, significant severe incidences of flooding events have already been experienced. However, there is dearth of evidence regarding vulnerability of households living in informal settlements in the city to the health risks of flooding and households' coping mechanisms. The study participants were randomly drawn from three purposively selected informal settlements in Mombasa City. Health vulnerability was assessed in terms of flood exposure, flood sensitivity, and flood adaptive capacity. While adaptation measures were explored based on the autonomous steps that household have adapted in response to flooding. Primary data were collected using questionnaires, Key Informant Interviews and Focus Group Discussions. The findings showed that up to $40.8 \%$ of the households had a high level of vulnerability, $46.9 \%$ had a medium level, while only $12.3 \%$ had low level of vulnerability. The findings also showed that household characteristics, water, sanitation and environmental risk factors had an impact on the level of household vulnerability. As coping mechanisms, households had taken some adaptation measures like clearing trenches to unblock drainage channels and piling sand bags around the house. The study concludes that for poor people living in flood prone areas in urban setting, flood early warnings, flood preventive actions and long term mitigation strategies need to be strengthened since they are exposed to greater health problems. The findings of the study are expected to help communities and local support agencies to identify weaknesses, especially in adaptive capacities, and to indicate ways of reducing future health vulnerability of residents of informal settlements to flooding.
\end{abstract}

Keywords Adaptation measures $\cdot$ Flood $\cdot$ Health vulnerability $\cdot$ Households $\cdot$ Informal settlements · Mombasa

Fredrick Okoth Okaka

fredrickokaka@gmail.com

1 Department of Geography and GISc, University of Venda, Thohoyandou, South Africa 


\section{Introduction}

Floods are recognized to be the most frequent and devastating type of natural disaster worldwide and one of the major environmental challenges faced by many nations in the twenty-first century (Wakuma et al. 2009; Bich et al. 2011; Ding et al. 2013; Mumuni 2013). In the past three decades, floods alone worldwide have contributed to over 500,000 mortalities and resulted to financial losses of more than US\$500 billion (Kocornik-Mina et al. 2015). According to Otiende (2009), and Republic of Kenya (2007), floods are the leading hydro-meteorological disasters in East Africa, especially in Kenya. In the last 2 decades, major floods in Kenya have occurred in 1997-1998, 2002, 2003, 2006, 2008, 2010, 2012 and 2015. In Mombasa City in particular, flooding has become a frequent phenomenon that at times occurs more than twice in a single year with devastating impacts. This is particularly so due to its low lying nature (the altitude of Mombasa ranges between 0 and $45 \mathrm{~m}$ above the sea level) coupled with the impacts of climate change and altered pattern of precipitation (Awuor et al. 2008; Kebede et al. 2010; Moser et al. 2010; Okaka and OmondiP 2017), limited parks and other green spaces to absorb run-off, and poor drainage systems that are often clogged by waste materials. Significant flood events in the city have been recorded in 1997/1998, 2004, 2006, 2015 and, more recently, in May 2017 (Mghenyi 2017). According to Awuor et al. (2008), the 2004 Indian Ocean tsunami and the 2006/2007 flooding experienced on the Kenyan coast exemplify the level of risk that Mombasa City faces. In the 2006/2007 event, over 60,000 people were affected, 24 cases of cholera reported and important infrastructure damaged. Certain parts of the city flood almost every year, and this usually leads to loss of lives and property. For example, flooding is a major problem in most informal settlements in Mombasa. In slums like Ziwa la Ng'ombe, floods now occur in places where they did not two decades ago (Moser et al. 2010).

According to Alderman et al. (2012), floods have serious consequences on community health and household well-being. The health effects are complex and far reaching and may include physical injury and even mortality. These impacts go beyond the immediate consequences arising from the direct health effects and include long-term impacts on community and household livelihood and environment that take place through multiple pathways including hazards from exposure to storm, displacement of people and interruption of services including healthcare programs, exposure to secondary hazards such as polluted drinking water, moulds in the house, mental health effects such as psychological distress, anxiety and depression due to traumatic or stressful experience during and after the floods (Lane et al. 2013). The recognized immediate health effects of flooding include injury, drowning, skin infections, worsening asthma, outbreaks of gastroenteritis and infectious diseases and respiratory infections (Bich et al. 2011; Baxter et al. 2001). The extent of the health impacts of flooding depends on the level of vulnerability and adaptation options of a household. Different households even within the same community may display different levels of vulnerability. The concept of vulnerability, according to Few (2003) and WHO (2003), refers to a relative incapacity to endure the effects of unfavourable environment, and the level of vulnerability hinges on the degree of exposure to a hazard, the magnitude to which its impacts are experienced, and the capacity for dealing with and adapting to these experiences. Health vulnerabilities to floods in Mombasa City, and in particular, in the informal settlements (which are mainly located within the major flood-prone areas) are changing as a result of many factors. During a flood, environmental hazards expose households to altered conditions which also change many determinants of well-being, including health. As a result of these changes, household 
vulnerability to flooding is revealed (Hashizume et al. 2008: Srikuta et al. 2015). Household demographics, conditions of housing, sanitation and other environmental factors may predispose different households to different levels of health vulnerability to flooding. Vulnerability is a dynamic status and requires to be understood within different contexts (Steinfu" hrer et al. 2009). According to Srikuta et al. (2015), "understanding health vulnerability to flooding at household level can help to strengthen household and community public health responses to a flood and lead to the development of preventive action to minimize suffering by increasing the adaptive capacity of households and the wider community" (p. 744). There has been no recent empirical study of health vulnerability at the household level in Mombasa City, and specifically, none focusing on flood-prone informal settlements in the city. This study aims to fill this gap by assessing the present health vulnerability of households to floods and their adaptation measures in flood-prone informal settlements in Mombasa City in Kenya. Borrowing from WHO (2003) and WHO (2013), vulnerability will be deemed to have three components: flood exposure, the extent to which households had experienced the impacts of flooding; flood sensitivity, the degree to which a household had been affected (health-wise) by flood exposure (the health effects may be direct or indirect); and flood adaptive capacity, the potential ability of a household to cope with the health consequences of a flood.

In theoretical perspective, Birkmann (2013) points out that different views on vulnerability are displayed in various concepts and frameworks and can be classified in different schools of thought that include: the school rooted in political economy and which addresses issues of the wider political economy; the school that focuses on the notion of coupled human-environmental systems and are linked to a socio-ecological perspective and socio-ecology; school of vulnerability that sees vulnerability and disaster risk assessment from a holistic view; school of vulnerability that integrates adaptation and coupling processes into a feedback-loop system and process-oriented perspective of vulnerability; school of vulnerability that combines framework of disaster risk research and climate change adaptation; and school vulnerability that emerged within the context of climate change science and adaptation research and which focuses on exposure, sensitivity and adaptive capacities as key determinants of vulnerability. The current study takes vulnerability as envisaged in this last school of thought.

The assessment of vulnerability depends very much on how it is defined and approached and also on the nature of the hazard as well as the perspective of the school of thought. Some studies use models, while others use statistical approaches which are deemed to require less data than simulation issues (Fellman 2012). Deressa et al. (2009) assess household vulnerability to climate change in the Nile Basin of Ethiopia by estimating the probability that a given shock or sets of shocks will move a household's income below the poverty threshold or force the income level to stay below the threshold if it is already below this level. Rayhan (2010) employs a similar approach which uses vulnerability as expected poverty to estimate vulnerability to floods of households in Bangladesh. In the current study, household's health vulnerability is looked at in the narrowest sense of the degree to which households are unable to cope with the adverse health outcomes and health impacts due to flood (Srikuta et al. 2015). This is taken to have the three components: flood exposure, flood sensitivity and flood adaptive capacity. 


\section{Study setting and methods}

Mombasa city has been in existence for many centuries. Documentary evidence shows that it was a prosperous trading town in the twelfth century and was a key node in the complex Indian Ocean trading networks (Williams et al. 1996). Mombasa is the second largest city in Kenya and the largest town situated in the Kenyan coast. It doubles up as a county. The coastal city lies in the south-eastern part of Kenya $\left(39.7^{0} \mathrm{E}\right.$ and $4.1^{0}$ South). It borders Kilifi County to the North, Kwale County to the South and West and the Indian Ocean to the East. The city covers land area of $229.9 \mathrm{~km}^{2}$ and $65 \mathrm{~km}^{2}$ of water mass (Mombasa County Government 2013). The city lies on a coastal plain which has a variable width ranging from 4 to $6 \mathrm{~km}$ (Kebede et al. 2010) and hardly rises above $50 \mathrm{~m}$ above sea level which exposes it to the dangers of sea level rise and flooding.

The climate of Mombasa is influenced by South East Monsoon winds (blowing between April and September) and the North-East Monsoon (October to March) and oceanic influence with the rainfall pattern being characterized into long rains (April-June with an average of $1040 \mathrm{~mm}$ and short rains (end of October-December with an average of $240 \mathrm{~mm}$ ) (Mombasa County Government 2013). The annual rainfall is $640 \mathrm{~mm}$. The annual mean temperature is $27.9{ }^{\circ} \mathrm{C}$ with a minimum of $22.7{ }^{\circ} \mathrm{C}$ and a maximum average of $33.1{ }^{\circ} \mathrm{C}$. The hottest month is February with a maximum of $33.1{ }^{\circ} \mathrm{C}$, while the lowest temperature is in July with a minimum average of $22.7^{\circ} \mathrm{C}$. However, of late, the climate of the city has been characterized by variability in terms of unexpected heavy rains causing flooding and prolonged droughts (Mombasa County Government 2013).

The population of the city stands at 939,370 according to 2009 census with a density of 4292 people per square kilometre and a total of 40,984 households (Commission of Revenue Allocation 2011). In 2012, the population was projected to be $1,051,825$; current estimates put the population at 1.2 million. According to Mombasa County Government (2013), the population is increasing rapidly in the unplanned areas and in areas that have a deteriorated, inadequate or outright non-existent sanitation infrastructure. This situation exposes most Mombasa City residents to great risk of flooding and associated health impacts.

The study was conducted between November 2017 and February 2018. The design that was utilized in this study was a cross-sectional survey design that utilizes mixed method approach. The mixed method was a concurrent sequential where both qualitative and quantitative data are collected at the same time. The study was conducted in three informal settlements of Ziwa la Ng'ombe, Moroto and Bangladesh in Mombasa City. These informal settlements are located in low lying areas that are prone to flooding. The settlements have been experiencing perennial flooding, sometimes twice in a year. The study participants were the heads of households who have lived in informal settlements for the past three consecutive years and above. Also included in the study were key informants that included public health workers and County Director in-charge of disaster management. The households were selected using systematic random sampling. The number of households sampled in each settlement was proportional to its contribution to the total number of households in the three settlements. Where no suitable participant was available (such as in a situation where nobody was found in the house or the head of the household had not lived in the area for the last three consecutive years or only children under age 18 years were found), the interviewers approached the next household.

The study utilized three research instruments: questionnaire, Focus Group Discussions (FGDs) and Key Informant Interviews (KIIs). The questionnaire was used to gather 
Table 1 Categorization of total scores for flood vulnerability components

\begin{tabular}{llll}
\hline Level & Exposure & Sensitivity & Adaptive Capacity \\
\hline Low & $1-7$ & $1-8$ & $1-16$ \\
Medium & $8-14$ & $9-16$ & $17-32$ \\
High & $15-21$ & $17-24$ & $33-48$ \\
\hline
\end{tabular}

Source: Adopted and modified from Srikuta et al. (2015)

\begin{tabular}{llll}
\hline Flood exposure & \multicolumn{2}{l}{ Flood sensitivity } \\
\cline { 2 - 4 } & High & Medium & Low \\
\hline High & High & High & Medium \\
Medium & High & Medium & Low \\
Unemployed & Medium & Low & Low \\
\hline
\end{tabular}

Source: Adopted from Srikuta et al. (2015)
Table 2 Decision matrix for determining a household flood risk level

information on socio-demographic characteristics of respondents, health vulnerability based on items measuring exposure (seven items), sensitivity (eight items) and adaptive capacity (16 items), and adaptation measures. The response option for each item for the three components of vulnerability was scored from 0 to 3 (none, low, medium and high) in terms of increasing levels of response to an item (Srikuta et al. 2015). The FGDs were used to gather information about participants' general health linkage with flooding and how the community responded to disaster. The FDGs consisted of 6 to 10 heads of households taking care of age and gender. In total, there were six FGDs ( 2 for each for the three informal settlements, i.e. repeated for each area). Public health officers provided key information on health risks posed by flooding in the area and public health response and barriers. Three public health officers (1 each for the three informal settlements) participated in the study. County government Director of Disaster Management provided information on the state of disaster preparedness and challenges they encounter.

Primary data obtained using the questionnaires were analysed using both descriptive statistics. Descriptive statistics involved the use of frequencies, totals and percentages. These were used to depict the extent of household health vulnerability to flooding and the adaptation strategies they have devised to cope. Individual household level of vulnerability was determined by using the formula as follows adopted from Adger (2006) and Srikuta et al. (2015):

$$
\text { Vulnerability }=\frac{\text { Risk }}{\text { Adaptive capacity }}
$$

where Risk $=$ Exposure $\times$ Sensitivity

Initial analysis involved categorization of the three components based on the total component score as shown in Table 1.

A decision matrix was then used for determining a household's flood risk level (Table 2) and finally individual household levels of health vulnerability (Tables 3, 4) (Srikuta et al. 2015).

Qualitative analysis considered the inferences that were made from the opinions of the participants during the KIIs and FGDs. The qualitative data were transcribed and analysed 
Table 3 Decision matrix for determining a household health vulnerability level

Table 4 Demographic characteristics of the respondents

\begin{tabular}{llll}
\hline Flood adaptive capacity & \multicolumn{2}{l}{ Flood risk level } \\
\cline { 2 - 4 } & High & Medium & Low \\
\hline High & High & High & Medium \\
Medium & High & Medium & Low \\
Unemployed & Medium & Low & Low \\
\hline
\end{tabular}

Source: Adopted from Srikuta et al. (2015)

\begin{tabular}{|c|c|c|}
\hline Household characteristics of respondents & Frequency & $\%$ \\
\hline \multicolumn{3}{|l|}{$\operatorname{Sex}$} \\
\hline Male & 225 & 57.7 \\
\hline Female & 165 & 42.93 \\
\hline \multicolumn{3}{|l|}{ Age Category (years) } \\
\hline $18-30$ & 181 & 46.4 \\
\hline $31-40$ & 119 & 30.5 \\
\hline $41-50$ & 63 & 16.2 \\
\hline $51-60$ & 18 & 4.6 \\
\hline 61 and above & 9 & 2.3 \\
\hline \multicolumn{3}{|l|}{ Marital Status } \\
\hline Married & 290 & 74.4 \\
\hline Single & 71 & 18.2 \\
\hline Divorced/Separated & 20 & 5.1 \\
\hline Widowed (widows and widowers) & 9 & 2.3 \\
\hline \multicolumn{3}{|l|}{ Educational attainment } \\
\hline No formal education & 34 & 8.7 \\
\hline Primary & 92 & 23.6 \\
\hline Secondary & 197 & 50.5 \\
\hline Tertiary & 64 & 16.4 \\
\hline University & 3 & 0.8 \\
\hline \multicolumn{3}{|l|}{ Occupation } \\
\hline Agriculture & 9 & 2.3 \\
\hline Fishing & 30 & 7.7 \\
\hline Small trader & 92 & 23.6 \\
\hline Civil servant & 13 & 3.3 \\
\hline Wharf/Dock & 28 & 7.2 \\
\hline Artisan/Jua Kali & 87 & 22.3 \\
\hline Unemployed & 131 & 33.6 \\
\hline \multicolumn{3}{|l|}{ Size of household } \\
\hline $1-5$ & 324 & 83.1 \\
\hline $6-10$ & 52 & 13.3 \\
\hline 11 and above & 14 & 3.6 \\
\hline
\end{tabular}


deductively through themes guided by the research objectives, and links between the data were identified through key patterns that emerged. This analysis, for example, aided in vividly capturing the residents' view on how their housing and sanitation situations predispose them to negative health outcomes from harsh climatic events. It was also useful in unearthing details on the various strategies households have devised to cope with negative consequences of climate change.

\section{Results}

\subsection{Demographic and other household characteristics}

The demographic and other household characteristics of the households are shown in Tables 3,4 . The results show that most respondents were male $(57.7 \%)$, while $42.3 \%$ were female.

The excess of males over females can largely be explained by the presence of males in the settlements whose families live elsewhere (e.g. upcountry). In the population, majority were falling in the age category of between 18 and 30 years (46.4\%), this decreased upwards with those aged 61 years and above forming the smallest proportion (2.3\%). Most respondents were married $(79.2 \%)$, however, with slightly more males $(5.3 \%)$ than females (4.8\%) being unmarried. Over 33\% of the respondents reported not engaging in employment, with a high $45.1 \%$ for females compared with $24.4 \%$ for males. The level of education of most respondents was either secondary (50.5\%) or primary (23.6\%), while $8.7 \%$ had no formal education. Most households comprised of 1 to 5 members (83.1\%) and up to $12.3 \%$ reporting having a member with chronic illness and $6.9 \%$ have at least one member with disability.

\subsection{Housing, sanitation and environmental conditions around the house}

The three informal settlements selected for this study are situated in flood-prone areas. According to the results presented in Table 5, a large number of respondent households (70.5\%) live in semi-permanent houses and use pit latrines $(90.3 \%)$. The main sources of water for domestic use are bore-hole (48.5\%) and water vendors (41.5\%). Most households dump their solid waste very far outside the house (69.0\%) and also pour waste water anywhere outside the house (83.6\%). Majority of the respondent households (73.8\%) reported that drainage system is non-existent in their area of resident.

What was more salient during FGDs were that the housing, sanitation and the general environmental conditions were not favourable and would easily contribute to outbreak and rapid spread of diseases during flooding event. One female participant lamented that the house they occupy is structurally weak because its walls are made of mud held by sticks, and they always have to rebuild after every heavy rains accompanied by flooding. In another of the FGDs, elderly senior residents observed that they use pit latrines that are shared by many households, and at night because of insecurity, they become risky for women and children who are forced to either relieve themselves in buckets or on the open sea front. The participants also decried lack of drainage system in the area, a situation that accelerated the flow of rain water into their homes even during normal amount of rainfall. Water situation was also a major concern for the participants. A female participant in one of the FGDs pointed out that "We rely on water vendors who charge exorbitant prices for 
Table 5 Sanitation and environment conditions around the house

\begin{tabular}{|c|c|c|}
\hline Situation & Frequency & $\%$ \\
\hline \multicolumn{3}{|l|}{ Type of house } \\
\hline Permanent (stone brick) & 72 & 18.5 \\
\hline Semi-permanent (e.g. mud wall, iron sheet) & 275 & 70.5 \\
\hline Makuti roofing with either stone or mud wall & 36 & 9.2 \\
\hline Polythene/wooden shack & 7 & 1.8 \\
\hline \multicolumn{3}{|l|}{ Type of toilet } \\
\hline Pit latrine & 352 & 90.3 \\
\hline Flash toilet & 27 & 6.9 \\
\hline Portable polythene bags & 8 & 2.1 \\
\hline Others, e.g. using open area next to sea shore & 3 & 0.8 \\
\hline \multicolumn{3}{|l|}{ Main Source of Water } \\
\hline Bore-hole & 189 & 48.5 \\
\hline Buying from vendors (at water points or hawked) & 162 & 41.5 \\
\hline Piped water & 31 & 7.9 \\
\hline Shallow well & 8 & 2.1 \\
\hline \multicolumn{3}{|l|}{ Disposal of solid waste disposal of solid waste } \\
\hline Throw anywhere outside the house & 23 & 5.9 \\
\hline Dump very far outside the house & 269 & 69.0 \\
\hline It is regularly collected by a garbage truck & 34 & 8.7 \\
\hline It is infrequently collected by a garbage truck & 13 & 3.3 \\
\hline I pay someone to go dump garbage & 31 & 7.9 \\
\hline Have dug a pit outside the house where garbage is dumped & 10 & 2.8 \\
\hline Burn the garbage & 10 & 2.8 \\
\hline \multicolumn{3}{|l|}{ Disposal of waste water } \\
\hline Pour in a container inside the house and pour out later & 20 & 5.1 \\
\hline Pour outside the house & 326 & 83.6 \\
\hline Have a drainage system/pipe in the house that carries the waste water & 28 & 7.2 \\
\hline Have dug a pit outside where waste water is poured & 16 & 4.1 \\
\hline \multicolumn{3}{|l|}{ State of drainage around the house } \\
\hline Non-existent & 288 & 73.8 \\
\hline There is planned water drainage system that works & 16 & 4.1 \\
\hline There is planned water drainage system but filled with garbage & 62 & 15.9 \\
\hline I have dug tunnel to divert water around the house & 24 & 6.2 \\
\hline
\end{tabular}

poor people like us; to make it worse we even do not know the source of the water. We just consume it hoping that God will protect us". Another participant said that "We get our water from wells, but these get flooded with dirty water during floods and we still have to draw water from them because we have no other alternatives".

Interview with public health officials confirmed that sanitation and environmental conditions of the informal settlements were unhygienic which predisposes the households to infectious diseases, a situation which they say becomes epidemic when flood occurs. "In the area where I work despite our concerted effort to weed out the practice, there is open defecation next to the sea by children during the day and adults at night 
fall. The residents complain that they do not have enough latrines and there is no space to construct more latrines. Some of the homes where the residents live in are in dilapidated state, which is a health hazard". One public health officer said.

\subsection{Vulnerability to flooding}

\subsubsection{Flooding exposure}

As shown in Table 6, most households (72.6\%) rated the last floods they experienced in their area of residence to have lasted for less than 2 weeks, $23.1 \%$ noted that last floods

Table 6 Flood exposure

\begin{tabular}{lll}
\hline Constructs of exposure & F & $\%$
\end{tabular}

Duration of last flooding phenomenon in the area

Less than 2 weeks 283

2-4 weeks

Over 4 weeks

Number of times the household had experienced flooding in the last 3 to 5 years

Once

Twice

Three times

More than three times

Flood level during the last flooding phenomenon in the area

Less than $30 \mathrm{~cm}$

31 to $10 \mathrm{~cm}$

Over $100 \mathrm{~cm}$

Flood area around the house

No flood around the house

Less than $10 \%$ of the area around the house

11 to $50 \%$ area around the house

Over $50 \%$ of area around the house

Flooding in the house

No flood in the house

Less than $10 \%$ of the house

11 to $50 \%$ of the house

Over $50 \%$ of the house

Assets damaged

No asset damaged

Less than $10 \%$ of asset damaged

11 to $50 \%$ asset damaged

Over $50 \%$ asset damaged

Recovery time

No need for recovery

Less than one week 
lasted for 2 to 4 weeks, while $4.4 \%$ reported that it had lasted for over 4 weeks. Across the three residential areas, the most reported duration of the last flooding was less than 2 weeks (Moroto 69.2\%, Bangladesh 70.0\% and Ziwa La Ngómbe 78.5\%). Most households $(89.5 \%)$ have experienced flooding more than three times in the last 3 to 5 years, and this was the case across the three residential areas (Moroto 76.9\%, Bangladesh $98.2 \%$ and Ziwa La Ngómbe $87.5 \%$ ). More than $49 \%$ of the households reported flood level of 31 to $100 \mathrm{~cm}$ during the last floods in the area. Flood level of over $100 \mathrm{~cm}$ was reported mainly in Ziwa La Ngómbe (40.8\% of households) as compared to Moroto (21.5\%) and Bangladesh (16.9\%). For many of the households (50.0\%), the last floods covered an area of 11 to $50 \%$ around the house. However, Ziwa La Ngómbe settlement had the highest number of households that had over $50 \%$ of the area around the house covered by flood (33.8\%) as compared to Moroto (14.6\%) and Bangladesh (13.1\%).

Majority of the households (41.8\%) had 11 to $50 \%$ of their houses flooded, while only $13.1 \%$ did not have flood water inside their house. Again majority of households who had over $50 \%$ of their houses flooded came from Ziwa La Ngómbe settlement (25.4\%) followed by Moroto (11.5\%) and lastly Bangladesh (10.0\%). Most households $(85.4 \%)$ had at least some of their assets damaged by flooding. When asked how long it took them to recover from the flood, majority of the respondents (46.4\%) reported that it took 1 to 4 weeks' time; however, up to $12.3 \%$ indicated that it took over 4 weeks to recover. In overall, based on the seven exposure items (the extent to which households had experienced the impacts of flooding), most households (58.5\%) reported a medium-level exposure to flooding (Table 7).

\subsubsection{Flood sensitivity}

Flood sensitivity, the degree to which a household had been affected health-wise, was captured using various parameters (Table 8). In terms of physical health, most households had some family members sick but did not need to see a doctor as they recovered after a few days $(45.1 \%) ; 16.9 \%$ had some members sick but recovered in 1 to 4 weeks and up to $8.7 \%$ had some members sick and took more than 4 weeks to recover or passed on. Majority of the respondent households (55.4\%) had felt stressed as a result of the floods but felt better after 1 to 4 weeks, while up to $5.6 \%$ took longer (more than 4 weeks) to recover from mental stress brought about by flooding and needed counselling. More than $60 \%$ of the households had problems getting clean drinking water and either needed special measure to obtain clean drinking water $(43.8 \%)$ or completely lacked clean drinking water (16.9\%), thereby exposing them to dangers of waterborne diseases. Another daily hardship was getting food during the duration of floods, with $13.3 \%$ of households lacking food, while $20.3 \%$ needed special measure to find food. A further health threat was the problem of waste management. Most households needed special measures to dispose of their waste and sewage $(60.8 \%$ ), while up to $22.6 \%$ could not properly dispose of their waste and

Table 7 Household flood exposure level

\begin{tabular}{lcr}
\hline Exposure & Frequency & $\%$ \\
\hline High & 46 & 11.8 \\
Medium & 228 & 58.5 \\
Low & 116 & 29.7 \\
Total & 390 & 100.0 \\
\hline
\end{tabular}


Table 8 Sensitivity to flooding

Constructs of flood sensitivity

F $\%$

Physical health impacts

No family member was sick

Some family members were sick but no need to see the doctor/recovered within a week

Some family members were sick and recovered within 1-4 weeks

Some family members were sick and recovered after more than 4 weeks/died

Mental health impacts

No stress or no mental health impacts

Felt stressed and felt better within a week

Felt stressed and felt better after $1-4$ weeks

Felt stressed and felt better after more than 4 weeks/needed to see a psychologist

Drinking water

No impact

Little impacts but easy to recover

There were some impacts and needed special measures to access clean drinking water (e.g.

boiling/purification)

Hard to find clean drinking water/lack of clean drinking water

Water use impacts

No impact

Little impacts but easy to recover

Hard to find clean water/lack of clean water for general use

Food supply impacts

No impact

Little impacts but easy to recover

There were some impacts and needed special measures to find food

Hard to find food/lack of food

Waste and sewage management impacts

No impact

Little impacts but easy to recover

There were some impacts and needed special measures to dispose of waste and sewage

Hard to dispose of waste and sewage/no proper disposal

Healthcare accessibility impacts

No impact

Little impacts but easy to recover

$\begin{array}{llll}\text { There were some impacts and needed to put more effort into accessing healthcare service, e.g. } & 87 & 22.3\end{array}$ wading into flood water over long distance

Hard to access healthcare service/could not access healthcare service

\section{Livelihood impacts}

No impact

Little impacts but easy to recover or able to work as normal 
Table 9 Household flood sensitivity level

\begin{tabular}{lcc}
\hline Sensitivity & Frequency & $\%$ \\
\hline High & 71 & 18.2 \\
Medium & 234 & 60.0 \\
Low & 85 & 21.8 \\
Total & 390 & 100.0 \\
\hline
\end{tabular}

\begin{tabular}{lcr}
\hline Sensitivity & Frequency & \multicolumn{1}{c}{$\%$} \\
\hline High & 27 & 6.9 \\
Medium & 227 & 58.2 \\
Low & 136 & 34.9 \\
Total & 390 & 100.0 \\
\hline
\end{tabular}

Table 10 Household flood risk level

sewage. Accessing healthcare facilities was a problem to some households, where $13.1 \%$ found it hard or could not completely access healthcare services, while $22.3 \%$ needed to put more effort in accessing healthcare services by sometimes wading through flood water. In earning their daily livelihoods, over $50 \%$ of respondent households needed to carry out additional work and at least $13.1 \%$ either found it hard to work or could not do any work.

In overall, in terms of sensitivity, the results in Table 9 show that most respondent households (78.2\%) reported medium-to-high levels of flood sensitivity.

\subsubsection{Flood risk level}

Flood risk level was arrived at by use of the matrix in Table 2 that was derived from multiplying flood exposure and sensitivity, and based on this, a decision was made whether the level of the risk was low, medium or high (Table 10). Most respondent households $(65.1 \%)$ were at medium-to-high risk level of flooding.

\subsubsection{Adaptive capacity}

Table 11 presents respondent's adaptive capacity to health impact of climate change based on various constructs (16 items). Most respondent households (71.5\%) reported lack of preparedness for general health risks of flood impacts. The same case was noted for mental health preparedness where most (68.7\%) of households reported lack of preparedness. Majority of respondent households (45.9\%) have never adjusted health behaviour during flooding. Around $38.5 \%$ reported that only unwell family members have adjusted health behaviour during flooding and a small percentage $(15.1 \%)$ indicated that all family members have adjusted health behaviour during flooding, but only in the beginning of a flood event. In terms of shelter preparedness, $44.1 \%$ of households had not prepared the house for any possible impact of flood, $39.5 \%$ had sometimes made some little preparation depending on the situation such as piling sand bags and making trenches, $14.4 \%$ made temporary shelter preparedness such as relocating belongings and raising the door steps, while only $2.1 \%$ made permanent shelter preparedness such as elevating the house or/and constructing the house with water proof materials. 
Table 11 Adaptive capacity

Constructs of adaptive capacity

F $\%$

Overall general health preparedness for flood impact

No need to prepare/not prepared

$279 \quad 71.5$

Prepared for some activities due to health risks of flood impacts

$82 \quad 21.0$

Prepared for most activities due to health risks flood impacts

$20 \quad 5.1$

Set up an emergency plan and prepared for most activities due to health risks of flooding

$9 \quad 2.3$

Mental health preparedness for flood impact

No need to prepare/not prepared

Some family members able to cope with mental health impacts

Most of family members able to cope with mental health impacts

$40 \quad 10.3$

All family members able to cope with mental health impacts and resilience to impacts

Health behaviour adjustment to flooding

Never adjust health behaviour during flooding

Only unwell family members have adjusted health behaviour during flooding of a flood event

All family members have always maintained health and shown good health behaviour

Shelter preparedness for flood impact

No shelter preparedness for flood

Shelter preparedness to flood sometimes/depends on the situation

Temporary shelter preparedness for flood (e.g. belongings relocated to high ground, clearing

Permanent shelter preparedness to flood (e.g. elevating the house, construct house with waterproof material

Sufficient clean water that can last 3 days during disaster

No access to clean water

Have clean water but not sufficient to last 3 days

Sometimes have sufficient clean water

Adequate sufficient clean water

Sufficient food that can last 3 days during disaster

No access to food

Sometimes have sufficient food

No access

Limited access

Sometimes have access

Always have access

Equipment for response to flood

No equipment

Have equipment for response to flood but not enough

Have enough equipment for response to flood but not sure if they work

Have enough equipment for response to flood and am sure they work

Family have evacuation plan

No evacuation plan 
Table 11 (continued)

Constructs of adaptive capacity

F $\%$

Family thought about evacuation plan but not seriously

$10 \quad 2.6$

Family has evacuation plan but never practiced it

Family has evacuation plan and has practiced it

$0 \quad 0.0$

Knowledge or skills of family members on how to respond to flood

No knowledge or skills on how to respond to flood

Only one of the family members has knowledge or skills on how to respond to flood

Most family member have knowledge or skills on how to respond to flood

$10 \quad 2.6$

All family members have knowledge or skills on how to respond to flood

Communication between household and community leaders

No communication between household and community leaders

Household sometimes communicates with community leaders

Household always communicates with community leaders by one way communication

Household always communicates with community leaders by two way communication

Access to financial asset (income, loans, membership to insurance)

No access to finance during flooding disaster

Little access to financial asset during flooding disaster

Sometimes have access to financial asset during flooding disaster

Always have access to financial asset during flooding disaster

External household support

No external household support

Receive support from community

Sometimes receive support from community, government agencies and private sector

Always receive support from community, government agencies and private sector

Membership to social group

No a member

Sometimes join a social group

Part-time membership to social group

Permanent membership to a social group

Community meetings

Not at all

Rarely

Sometimes

Always

Access to electricity

Not at all

Rarely

Sometimes

Most of the households (63.3\%) do not have access to sufficient clean water that can last 3 days during disaster. Up to $13.3 \%$ would not completely access clean water. In terms of having sufficient food that can last 3 days during a disaster, again majority of the households reported that they do not have sufficient food that can last that 
time. While 9.5\% do not have access to food at all. In regard to tools and equipment, majority of the households have no access to tools such as water pumps, floaters and access to ambulances (55.9\%) and equipment such as first aid kits, dykes and boots (77.4\%) that can help them effectively respond to the health risks of flooding. An overwhelming majority of households do not have evacuation plan (95.1\%) and lack skills or knowledge (91.5\%) on how to respond to health threat of flooding. Almost $50 \%$ of the respondent households (47.9\%) sometimes communicate with a community leader; however, about a similar number (49.7\%) reported that community meetings were rarely held in their neighbourhood. It was also noted that a large percentage of the households (73.1\%) do not belong to a social group that they can seek help during a disaster like flooding; this is despite most $(58.3 \%)$ indicating that they do not receive any external support and have no access to financial asset (73.3\%) such as loans and savings during flooding.

The general low level of adaptive capacity by most household became more apparent from the participants in the FGDs who expressed their general lack of access to resources and skills that can enable them cope with recurrent flooding and associated health risks. A female participant quipped that "The priority in my household is to put food on the table, which in itself is a daunting task, as we survive from hands to mouth, how can I even think about buying a first aid kit, will it feed my children, when floods come I grab my children and whatever I can lay my hand on and dash to any safe ground around".

In one of the settlements, the residents said that they no longer receive any external support during flood event; the last support they received was from Red Cross Society of Kenya that stopped way back in 2010. Lack of disaster preparedness was noted even at the county level where support should come from during a disaster like flooding.

An interview with the outgoing Director of Disaster Management in Mombasa County revealed that the department did not have a flood map of Mombasa County that indicated the level of flood risk in different areas. The department also did not have a specified call centre where the public could make inquiries about flood situation. In response to whether the department usually conducts training on basic knowledge of floods and early warning systems to the residents especially those living in flood-prone areas, the outgoing director said that actually it is their officers that they send for training; however, they rely on the Red Cross Society in Kenya to provide training and support to the public. The department merely coordinates these activities if need arises. He observed that the county officers in general seek help form local leaders and other agencies and help in distributing relief items during flooding disaster. On overall, most respondent households (85.4\%) reported a low level of adaptive capacity for coping with health impacts of flooding (Table 12).

Interviewed health officials decried low capacity from the health sector in providing health services during flood, due to being caught un-prepared, being overworked due to

Table 12 Household adaptive capacity level

\begin{tabular}{lcr}
\hline Adaptive capacity & Frequency & $\%$ \\
\hline High & 2 & 0.5 \\
Medium & 55 & 14.1 \\
Low & 333 & 85.4 \\
Total & 390 & 100.0 \\
\hline
\end{tabular}


small number of health personnel, lack of adequate facilities, particularly essential medicines and poor coordination of the different agencies. One public health officer opined that "there is always poor coordination during disaster in this area; no one knows who is incharge; everybody including politicians want to be the one seen doing something but without providing any technical support; we try to do our best but you know without enough personnel, equipment and facilities we can only pray that causalities are minimal".

\subsubsection{Health vulnerability to flood}

All households had been affected by flooding at some point in time in the past 3 to 5 years. Up to $40.8 \%$ had a high level of vulnerability to flooding, $46.9 \%$ had a medium level, while only $12.3 \%$ had low-level vulnerability (Table 13 ).

\subsection{The role of household characteristics, water, sanitation and environmental risk factors in the flooding - health vulnerability relationship in Mombasa}

The study further sought to establish the role of household characteristics, water sanitation and environmental risk factors in the flooding - health vulnerability relationship. Table 14 summarizes the results based on cross-tabulations between demographic characteristics of households and health vulnerability, while Table 15 presents the results on the basis of water sanitation and environmental risk factors.

The results of the study show that females, those aged 51 and above, those widowed, those with non-formal education, large household size, those with a family member with chronic illness and disability and small traders, were most likely to be highly vulnerable to the health risks of flooding than the other segments of the population. On the basis of water sanitation and environmental risk factors, the findings indicate that households living in makuti thatched (palm leaves roofing) and polythene or wooden shacks, those using portable polythene bags or open space as toilets, those drawing water from shallow well, and those with non-existent drainage systems, are more likely to be highly vulnerable to negative health risks of flooding as compared to the rest of the population. To test for the significance of these findings, the data were further subjected to Chi-square tests (at 0.05 level of significance) The results indicated that age differences $\left(\chi^{2}=42.933\right.$, Sig. 0.001), marital status $\left(\chi^{2}=13.934\right.$, Sig. 0.030), size of household $\left(\chi^{2}=13.026\right.$, Sig. 0.011) and whether a family had a member with chronic illness or not $\left(\chi^{2}=7.081\right.$, Sig. 0.029) were significant determinants of the level of vulnerability. On the other hand, Chi-square tests revealed that all the sanitation and environmental risk factors, type of housing $\left(\chi^{2}=14.516\right.$, Sig. 0.024), type of toilet $\left(\chi^{2}=13.235\right.$, Sig. 0.039$)$, main source of water $\left(\chi^{2}=23.306\right.$, Sig. 0.001) and state of drainage around the house $\left(\chi^{2}=12.872\right.$, Sig. 0.045) were significant determinants of the level of vulnerability.

Table 13 Level of household's health vulnerability to flood

\begin{tabular}{lcr}
\hline Health vulnerability & Frequency & $\%$ \\
\hline High & 159 & 40.8 \\
Medium & 183 & 46.9 \\
Low & 48 & 12.3 \\
Total & 390 & 100.0 \\
\hline
\end{tabular}


Table 14 The role of household demographic characteristics in the flooding - health vulnerability relationship in Mombasa

\begin{tabular}{|c|c|c|c|c|c|c|}
\hline \multirow[t]{3}{*}{ Characteristics } & \multicolumn{6}{|c|}{ Level of vulnerability } \\
\hline & \multicolumn{2}{|c|}{ Low } & \multicolumn{2}{|c|}{ Medium } & \multicolumn{2}{|c|}{ High } \\
\hline & $\mathrm{F}$ & $\%$ & $\mathrm{~F}$ & $\%$ & $\mathrm{~F}$ & $\%$ \\
\hline \multicolumn{7}{|l|}{ Sex } \\
\hline Male & 29 & 12.9 & 107 & 47.6 & 89 & 39.6 \\
\hline Female & 19 & 11.5 & 76 & 46.1 & 70 & 42.4 \\
\hline \multicolumn{7}{|l|}{ Age (years) } \\
\hline $18-30$ & 19 & 10.5 & 101 & 55.8 & 61 & 33.7 \\
\hline $31-40$ & 15 & 12.6 & 53 & 44.5 & 51 & 42.9 \\
\hline $41-50$ & 13 & 20.6 & 22 & 34.9 & 28 & 44.4 \\
\hline $51+$ & 1 & 4.2 & 4 & 16.7 & 19 & 79.1 \\
\hline \multicolumn{7}{|l|}{ Marital status } \\
\hline Single & 13 & 18.3 & 34 & 47.9 & 24 & 33.8 \\
\hline Married & 32 & 11.0 & 138 & 47.6 & 12 & 41.4 \\
\hline Divorced/Separated & 2 & 10.0 & 9 & 45.0 & 9 & 45.0 \\
\hline Widowed & 1 & 11.1 & 2 & 22.2 & 6 & 66.7 \\
\hline \multicolumn{7}{|l|}{ Level of education } \\
\hline Non-formal & 3 & 8.8 & 14 & 41.2 & 17 & 50.0 \\
\hline Primary & 9 & 9.8 & 40 & 43.5 & 43 & 46.7 \\
\hline Secondary & 20 & 10.2 & 97 & 49.2 & 80 & 40.6 \\
\hline Tertiary & 15 & 23.4 & 30 & 46.9 & 19 & 29.7 \\
\hline University & 1 & 33.3 & 2 & 56.7 & 0 & 0.0 \\
\hline \multicolumn{7}{|l|}{ Size of household } \\
\hline $1-5$ & 39 & 12.0 & 154 & 50.6 & 121 & 37.3 \\
\hline $6-10$ & 8 & 15.4 & 16 & 30.8 & 28 & 53.8 \\
\hline $11+$ & 1 & 7.1 & 3 & 21.4 & 10 & 71.4 \\
\hline \multicolumn{7}{|c|}{ Member of family with chronic illness } \\
\hline Family with & 3 & 6.2 & 22 & 45.8 & 23 & 47.9 \\
\hline Family without & 45 & 13.2 & 161 & 47.1 & 136 & 39.8 \\
\hline \multicolumn{7}{|c|}{ Member of family with disability } \\
\hline Family with & 1 & 3.7 & 11 & 40.7 & 15 & 55.6 \\
\hline Family without & 47 & 12.9 & 172 & 47.4 & 144 & 39.7 \\
\hline \multicolumn{7}{|l|}{ Occupation } \\
\hline Agriculture & 0 & 0.0 & 7 & 77.8 & 2 & 22.2 \\
\hline Fishing & 2 & 5.7 & 17 & 56.7 & 11 & 36.7 \\
\hline Small trader & 8 & 8.7 & 41 & 44.6 & 43 & 46.7 \\
\hline Civil servant & 8 & 61.5 & 4 & 30.8 & 1 & 7.7 \\
\hline Wharf/Dock worker & 3 & 10.7 & 13 & 46.4 & 12 & 42.9 \\
\hline Artisan/Jua Kali & 11 & 12.6 & 42 & 48.3 & 34 & 39.1 \\
\hline Unemployed & 16 & 12.2 & 59 & 45.0 & 56 & 42.7 \\
\hline
\end{tabular}

\subsection{Household adaptation measures to the health risk of flooding}

In addition to adaptive capacity, the study solicited information from the respondents on the adaptation measures they have taken in their households to cope with the flooding 
Table 15 The role of household water, sanitation and environmental risk factors in the flooding-health vulnerability relationship in Mombasa

\begin{tabular}{|c|c|c|c|c|c|c|}
\hline \multirow[t]{3}{*}{ Characteristics } & \multicolumn{6}{|c|}{ Level of vulnerability } \\
\hline & \multicolumn{2}{|c|}{ Low } & \multicolumn{2}{|c|}{ Medium } & \multicolumn{2}{|c|}{ High } \\
\hline & $\mathrm{F}$ & $\%$ & $\mathrm{~F}$ & $\%$ & $\mathrm{~F}$ & $\%$ \\
\hline \multicolumn{7}{|l|}{ Type of housing } \\
\hline Permanent (stone brick) & 20 & 27.8 & 41 & 56.9 & 11 & 15.3 \\
\hline Semi-permanent & 26 & 9.5 & 128 & 46.5 & 121 & 44.0 \\
\hline Makuti roofing & 1 & 2.8 & 13 & 36.1 & 22 & 61.1 \\
\hline Polythene/wooden shacks & 1 & 14.3 & 1 & 14.3 & 5 & 71.4 \\
\hline \multicolumn{7}{|l|}{ Type of toilet } \\
\hline Pit latrine & 34 & 9.7 & 164 & 47.4 & 151 & 42.9 \\
\hline Flash toilet & 14 & 51.9 & 12 & 44.4 & 1 & 3.7 \\
\hline Portable polythene bags & 0 & 0.0 & 3 & 37.5 & 5 & 52.5 \\
\hline Others, e.g. using open area next to sea shore & 0 & 0.0 & 1 & 33.3 & 2 & 56.7 \\
\hline \multicolumn{7}{|l|}{ Main source of water } \\
\hline Bore-hole & 15 & 7.9 & 93 & 49.2 & 81 & 42.9 \\
\hline Buying from vendors (at water points or hawked) & 14 & 8.6 & 79 & 48.8 & 69 & 42.6 \\
\hline Piped water & 19 & 61.3 & 9 & 29.0 & 3 & 9.7 \\
\hline Shallow well & 0 & 0.0 & 2 & 25.0 & 5 & 75.0 \\
\hline \multicolumn{7}{|l|}{ State of drainage around the house } \\
\hline Non-existent & 20 & 6.9 & 136 & 47.2 & 132 & 45.8 \\
\hline There is planned water drainage system that works & 4 & 25.0 & 12 & 75.0 & 0 & 0.0 \\
\hline There is planned water drainage system but filled with garbage & 15 & 24.2 & 31 & 50.0 & 16 & 25.8 \\
\hline I have dug tunnel to divert water around the house & 9 & 37.5 & 4 & 16.7 & 11 & 45.8 \\
\hline
\end{tabular}

menace in their area of residence. They were presented with a list of possible measure and were asked to indicate which one their households had adopted at any one time. The results are shown in Table 16. Most respondents cleaned their living area to avoid infestation by dangerous vectors $(65.1 \%)$. Up to $54.1 \%$ cleared trenches to unblock drainage channels, $52.1 \%$ always washed after exposure to flood water, $43.8 \%$ piled sand bags and or logs around the house, and $40.5 \%$ indicated that they stayed alert to warnings from neighbours on flooding situation.

Information provided by participants from the FGDs indicates that households devise various strategies to avoid the negative impacts of flooding, but these are limited by income and knowledge on disaster preparedness. A middle-aged male participant in one of the FGDs explained that "we have piled sand around our house and raised our door step to ward off the flood water, but this is not enough especially when the rain persist for days. If we had money we could raise the floor of our house and even waterproof the walls to make it safer". A female participant lamented that "we try our best by keeping items including utensils in raised racks in the house, but sometimes you do not know what else you can do to keep your children from becoming sick when flood come".

Interview with public health officers revealed that they distribute mosquito nets to pregnant women and educate the people who visit health facilities on best health practices, 
Table 16 Household adaptation measures

\begin{tabular}{lll}
\hline Adaptation measures & F & $\%$
\end{tabular}

Elimination of sources of vector-borne diseases

Cleaning of living area to infestation by dangerous vectors 254

Possession of nets for insect protection

Storage of insect repellents

Collection of refuse and proper disposal

Family healthcare

Always washing after exposure to flood water

Arranging and keeping essential medicines

Provision of boots

Seeking alternative accommodation for children and elderly

Provision for waste disposal

Storage of plastic bags for waste

Raised pit latrines

Clearing trenches to unblock drainage channels

Food and water supply management

Storage of clean water for drinking that can last for 3 days $\quad 60$

$\begin{array}{lc}\text { Storage of cooking fuel that can last for a week } & 108\end{array}$

Storage of water for general use

Storage of food that can last 3 days in advance

\section{Communication}

Frequent attention to communications about flood conditions from media, community leader and related agencies

Staying alert to warnings from neighbours

Call for assistance from neighbours or evacuation agencies

Arrangements for housing shelter and property

Piling soil on the ground floor

Elevating the house

Raised door steps

Making trenches in front of the house

Piling sand bags and/or tree logs

Relocation of belongings to high places

Securing structures with waterproof recycled materials

Clearing and extending water drainage system

Setting aside funds for emergency during flooding

Possession of evacuation kits

Seeking alternative living area in case of severe event

Household assets insurance

Making outlets at the rear of the house so water coming in flows out quickly

especially during floods as mitigation strategies. But they claimed that some of the beneficiaries of the nets sell them or use them in their vegetable gardens around their houses instead of the intended use. 


\section{Discussions}

The findings of the present study show that the housing, sanitation and environmental conditions of the areas where the respondent households lived were unhygienic. For example, most of the households live in semi-permanent house or makuti thatched (palm leaves roofing) or even polythene shacks. Most use pit latrines or portable polythene (famously known as flying toilet) and fetch their drinking water from bore-holes or from water vendors.

There was generally open dumping and pouring water anywhere outside the house and none-existent drainage. These conditions are deplorable and a fertile ground for disease outbreak. Therefore, in the event of flooding the conditions are heightened and a state of catastrophe arises. These conditions have been associated with many informal settlements in developing countries. Adelekan (2009) in a study of flooding in four slums in Lagos, Nigeria, observed that the households in the slums live in poor-quality housing and in environmentally degraded conditions, which lack water and sanitation infrastructure. In Keko Machungwa informal settlement in Dar es Salaam, Sakijege et al. (2012) noted that household environments are characterized by narrow or non-existent drainage, there is haphazard dumping of waste, poor-quality housing, and over $90 \%$ of households use pit latrines as toilets. Such conditions place informal settlement dwellers at great risk of disease outbreaks in the event of flooding.

The findings of this study indicated that the level of household health vulnerability to flooding ranged from mainly medium to high. By occupying low lying waste/marginal lands, households in the three informal settlements get exposed to flooding every time there are heavy rains, but due to poverty and lack of skills and support, their adaptive capacity is low. This is not helped by the fact that the sites of these settlements lack drainage facilities and other infrastructure because the existing plans of Mombasa town had no provisions for these poor neighbourhoods. In the current situation, little is expected from the county government of Mombasa because most counties under the devolved governance structure in Kenya lack the institutional capacity and resources to appropriately address these conditions. The county government of Mombasa has also not adequately invested in risk reduction to enhance disaster preparedness of these people living in the flood-prone informal settlements, thus increasing their health vulnerability to flooding. According to Tas et al. (2013), disaster management should prioritize the protection of people from possible flood disaster through enhanced disaster preparedness rather than only evacuation and recovery in order to minimize exiting disaster risk. The level of health vulnerability to flooding was found to vary between household groups. The most vulnerable groups of households were composed of women, the aged, those with a member of family with chronic illness or disability, those with low levels of education and small-scale traders and unemployed. Some of these groups of people like the aged, those with chronic illness or disability, would require special health care during flooding. But in general, all the listed groups of people in many societies normally are underprivileged and often require external support during disasters like flooding. However, from the FGDs it was clear that only a few people had received support during the last flooding incidences with those from Moroto indicating that they used to receive support from Red Cross Society of Kenya who also trained two members of the community in administering health support during emergencies, but the support stopped in 2010 and the two trained community health workers moved to other settlements. In a similar study by Srikuta et al. (2015) in rural flood-prone area of north-eastern Thailand, the vulnerability to health risk of flood was lower compared to those in the current study; however, they also observed that some groups of households were more vulnerable 
than others. The most vulnerable groups their study indicated were those with members of the family with chronic illness and or disability and also those with small children. But unlike in the current study, their study found that most households received support from local agencies, community health promotion hospitals, Thailand's Red Cross Society and local administration organization, thus reducing their vulnerability.

Lowe et al. (2013) reiterated that household health vulnerability to flooding differs in different contexts and varied levels of preparedness. They indicated that factors such as sex, age, existing illness, medication interruption, previous flood experiences and low education level and socio-economic status place individuals at higher risks. The interplay between these factors and timing and length of flooding days may complicate the situation but also could prompt households in taking some steps to reduce health impacts.

Households devise different autonomous adaptation strategies. The findings of this study showed that among the dominant strategies include cleaning of living area to avoid infestation by dangerous vectors, clearing trenches to unblock drainage channels, piling sand bags around the house and staying alert to warnings from neighbours. Adaptation strategies are determined by different factors that include income, educational levels, past flooding experiences, skills in disaster preparedness among other factors. Most households from the three informal settlements have low incomes and do not have right skills in disaster preparedness, and this limits their adaptation strategies.

Climate change adds a new and very dangerous dimension to flood hazards and health risks to individuals and the community. Urban population, especially those living in poor neighbourhood that are prone to floods, are at increased risk to the negative health impacts due increased incidences of flooding induced by climate change. In Kenya, where the study was situated, the National Climate Change Response Strategy indicated that climate change has influenced the spread of diseases such as malaria, diarrhoea, Rift Valley Fever and Dengue (Government of Kenya (GoK 2010).

To build resilience and manage the health impacts of increasing flooding due to climate change, it is critical for individuals, communities, governments and other stakeholders to plan ahead. Autonomous (or spontaneous) adaptations by individual households are mere stop gaps since they are usually reactive responses rather than preventive measures. Longterm adaptation (anticipatory or proactive or planned) that is informed by scientific information about projected occurrence of floods is important and requires initiation by different stakeholders inclusive of individual members of the community but with government agencies taking the centre stage.

To prepare well for increased incidences of flooding hazards, the health system needs to develop appropriate interventions such as early warning systems, effective prevention, development of flood health action plans and response capabilities as well as enhanced coordination with other sectors, experts and the community. Community engagement and participation are key in rolling out intervention programs and dissemination of information. Srikuta et al. (2015) argued that the requirement for the success of long-term disaster prevention and emergency preparedness is for all health and non-health agencies and the community to work collectively through well-coordinated process. Brilly and Polic (2005) underscored the need for multidisciplinary and integrated approach to flood mitigation before during and after flooding disaster. 


\section{Conclusions and recommendation}

The results of the study indicate that the housing, sanitation and environmental conditions of households in the three informal settlements are poor and that many had medium-tohigh levels of health vulnerability to flooding. It further indicates that high level of health vulnerability to flooding appears disproportionately borne by females, aged and households with a member with disability of chronic illness. Respondents' household had devised some adaptation measures to cope with the health impact posed by flood. Some of these included cleaning of living area to avoid infestation by dangerous vectors, clearing trenches to unblock drainage channel, piling sand bags around the house and staying alert to warning from neighbours. To reduce health vulnerability to flooding by households living in informal settlements, they would have to entail empowering households to take preventive actions. It should also entail providing accurate flood early warnings as well as equipping households with skills of how to respond to disaster. Finally, it requires enhanced coordination by various agencies providing help before, during and after flooding.

Acknowledgements This study was carried out with the aid of a research Grant from the Directorate of Research, University of Venda, South Africa.

Open Access This article is distributed under the terms of the Creative Commons Attribution 4.0 International License (http://creativecommons.org/licenses/by/4.0/), which permits unrestricted use, distribution, and reproduction in any medium, provided you give appropriate credit to the original author(s) and the source, provide a link to the Creative Commons license, and indicate if changes were made.

\section{References}

Adelekan IO (2009) Vulnerability of poor urban coastal communities to climate change in Lagos, Nigeria. In: 5th urban research symposium 2009

Adger WN (2006) Vulnerability. Glob Environ Change 6:268-281

Alderman K, Turner LR, Tong S (2012) Floods and human health: a systematic review. Environ Int 47:37-47

Awuor CB, Orindi VA, Adwera AO (2008) Climate change and coastal cities: the case of Mombasa, Kenya. Environ Urban 20(1):231-242

Baxter PJ, Moller I, Spencer T, Tapsell S (2001) Coastal flooding and climate change. In: Health effects of climate change in the UK: an expert review for comment. Department of Health, London, pp 177-187

Bich TH, QuangL Ha LT, Hanh TT, Guha-Sapir D (2011) Impacts of flood on health: epidemiologic evidence from Hanoi,Vietnam. Glob Health Action 4:6356. https://doi.org/10.3402/gha.v4i0.6356

Birkmann J (2013) Measuring vulnerability to natural hazards: towards disaster resilient societies, 2nd edn. United Nation University, Tokyo

Brilly M, Polic M (2005) Public perception of flood risks, flood forecasting and mitigation. Nat Hazards Earth Syst Sci 5:345-355

Commission of Revenue Allocation (2011) Kenya County fact sheets. Government of Kenya Printers, Nairobi

Deressa TT, Hassan RM, Ringler C (2009) Assessing household vulnerability to climate change: the case of farmers in the Nile Basin of Ethiopia. IFPRI discussion paper 00935

Ding G, Zhang Y, Gao L, Ma W, Li X et al (2013) Quantitative analysis of burden of infectious Diarrhea associated with floods in Northwest of Anhui Province, China: a mixed method evaluation. PLoS ONE 8(6):e65112. https://doi.org/10.1371/journal.pone.0065112

Fellman T (2012) The assessment of climate change related vulnerability in the agricultural sector: reviewing conceptual framework. In: FAO/OECD workshop on building resilience for adaptation to climate change in agricultural sector, Rome April 2012

Few R (2003) Flooding, vulnerability and coping strategies: local responses to a global threat. Prog Dev Stud 3:43-58 
Go K (2010) National climate change response strategy: executive brief. Ministry of Environment and Mineral Resources, Government of Kenya (GoK), Nairobi

Hashizume M, Wagatsuma Y, Faruque ASG, Hayashi T, Hunter PR, DA Armstrong Sack (2008) Factors determining vulnerability to diarrhea during and after severe floods in Bangladesh. J Water Health 6:323-332

Kebede AS, Hanson S, Nicholls RJ, Mokrech M (2010) Impacts of climate change and sea-level rise: a preliminary case study of Mombasa. Kenya, Tyndall Centre for Climate Change Research

Kocornik-Mina A, Thomas KJ, McDermott GM, Ferdinand R (2015) Flooded cities. CEP discussion paper 1398

Lane K, Guzman KC, Wheeler K, Abid Z, Graber N, Matte T (2013) Health effects of coastal storms and flooding in urban areas: a review and vulnerability assessment. J Environ Public Health 2013:1-13

Lowe D, Ebi KL, Forsberg B (2013) Factors increasing vulnerability to health effects before, during and after floods. Int J Environ Res Public Health 10:7015-7067

Mghenyi C (2017) Mombasa floods caused by poor planning. Star news may 11th

Mombasa County Government (2013) First county integrated development plan 2013-2017. Mombasa County Government, Mombasa

Moser C, Norton A, Stein A, Georgieva S (2010) Pro-poor adaptation to climate change in urban centres: Case studies of vulnerability and resilience in Kenya and Nicaragua. Report for Social Development Department. Washington D.C, World Bank

Mumuni A (2013) Flooding and diarrhoeal disease incidence in urban poor communities in Accra, Ghana: investigating the effects of risk perception measures. Doctoral thesis, University of Ghana

Okaka FO, OmondiP Odhiambo B D (2017) Urban residents' perception of health risks of climate change and its impact on behaviour change in Mombasa City, Kenya. Int J Humanit Soc Stud 5(2):248-257

Otiende B (2009) The economic impacts of climate change in Kenya: Riparian flood impacts and cost of adaptation

Rayhan MI (2010) Assessing poverty, risk and vulnerability: a study on flooded households in rural Bangladesh. J Flood Risk Manag

Republic of Kenya (2007) National Policy on Disaster Management. Ministry of Special Programmes, Nairobi

Sakijege T, Lupala J, Sheuya S (2012) Flooding, flood risks and coping strategies in urban informal residential areas: the case of Keko Machungwa, Dar es Salaam, Tanzania. Jamba J Disaster Risk Stud 4(1)

Srikuta P, Inmuong U, Inmuong Y, Bradshaw P (2015) Health vulnerability of households in flooded communities and their adaptation measures: case study in Northeastern Thailand. Asia Pac J Public Health 27(7):743-755

Steinfu "hrer A, Kuhlicke C, Marchi B, Scolobig A, Tapsell S, Tunstall S (2009) Local communities at risk from flooding: social vulnerability, resilience and recommendations for flood risk management. www. ufz.de/export/data/1/26010_Task11_Broschuere_7_09.pdf (Accessed 13 Feb 2018)

Tas M, Tas N, Durak S, Atnur G (2013) Flood disaster vulnerability in informal settlements in Bursa,Turkey. Environ Urban 25(2):443-463

Wakuma AS, Mandere N, Ewald G (2009) Floods and health in Gambella region, Ethiopia: a qualitative assessment of the strengths and weaknesses of coping mechanisms. Glob Health Action 2:1-10

WHO (2003) Methods of assessing human health vulnerability and public health adaptation to climate change. Regional Office for Europe; Health and Global Environmental Change Series No 1, Copenhagen

WHO (2013) Protecting health from climate change: vulnerability and adaptation assessment. World Health Organization, Geneva

Williams TM, Rees JG, Kairu KK and Yobe AC (1996) Assessment of contamination by metals and selected organic compounds in Coastal Sediments and Waters of Mombasa, Kenya. British Geological Survey, overseas geology series technical report WC/97/37

Publisher's Note Springer Nature remains neutral with regard to jurisdictional claims in published maps and institutional affiliations. 